\title{
The Functional Autism Connectome
}

\author{
Daniel J. Kelley \\ University of Wisconsin School of Medicine and Public Health \\ Neuroscience Training Program Defense Overview
}




\section{Autism}

Autism is a neurodevelopmental disorder of unknown etiology.

DSM-IV-TR Pervasive developmental disorders (PDDs)

Childhood disintegrative disorder

Rett' s disorder

Autistic disorder

Asperger' s disorder

Pervasive developmental disorder-not otherwise specified (PDD-NOS) 


\section{Autism}

Autism is a neurodevelopmental disorder of unknown etiology.

DSM-IV-TR Pervasive developmental disorders (PDDs)

Childhood disintegrative disorder

Rett' s disorder

Autistic disorder

Asperger' s disorder

Pervasive developmental disorder-not otherwise specified (PDD-NOS)

Autism Spectrum Disorders 


\section{Autism}

Autism is a neurodevelopmental disorder of unknown etiology.

DSM-IV-TR Pervasive developmental disorders (PDDs)

Childhood disintegrative disorder

Rett' s disorder

Autistic disorder

Asperger' s disorder

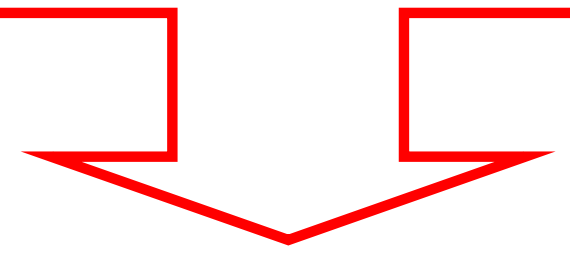

Autism 


\section{Epidemiology}

PDD: 1966 measure of 4/10,000 ; 2005 increase to 30-60/10,000 (Rutter, 2005)

ASDs:

PDD-NOS:

Autistic disorder:

Asperger' s disorder: $\quad 2.5 / 10,000$

$15 / 10,000$
$27.5 / 10,000$

10/10,000; male/female ratio of 4.3:1

(Fombonne, 2003)
ASDs versus Cancer Prevalence

Childhood ASDs (CDC, 2007)

$66.6 / 10,000$ or $1 / 150$

Childhood Cancer $(\mathrm{NCl}, 2005)$

$1.5 / 10,000$

http://www.cdc.gov/ncbddd/autism/faq_prevalence.htm
U.S. Autism Population Estimate 05/03/2008 03:09 PM PST

(ages 3-22)

260,293

U.S. Annual Economic Cost $\$ 7,808,816,443$

Next Diagnosis $2: 44$ mins

www.FightingAutism.org 
Autism Prevalence is Iotcreasing in US and Wisconsin Public Schools

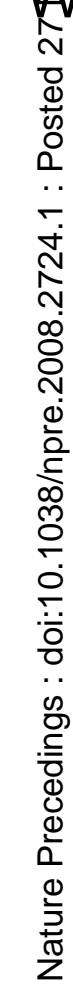

\section{Data Source:}

Individuals with Disabilities Education Act (IDEA)

Center for Disease Control (CDC)

http://www.fightingautism.org/ a U.S. Arut Dutlying Areas. Hutism Ages $5-22$

A U.S. Arot Dutlying Areas. Hut ism Hars $5-22$

Number of Cases

[ U.S. School Years $1992-2003$ ]
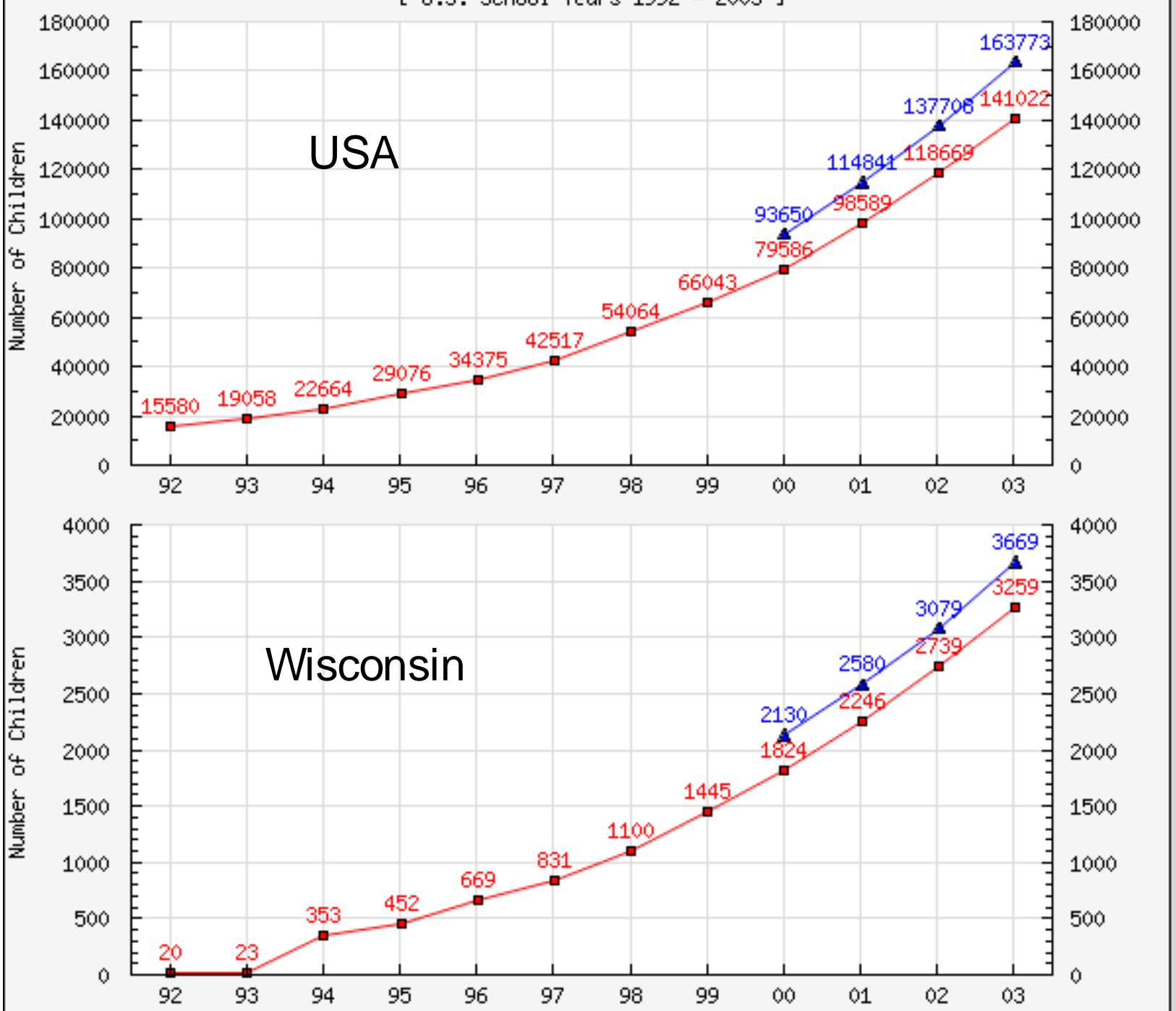


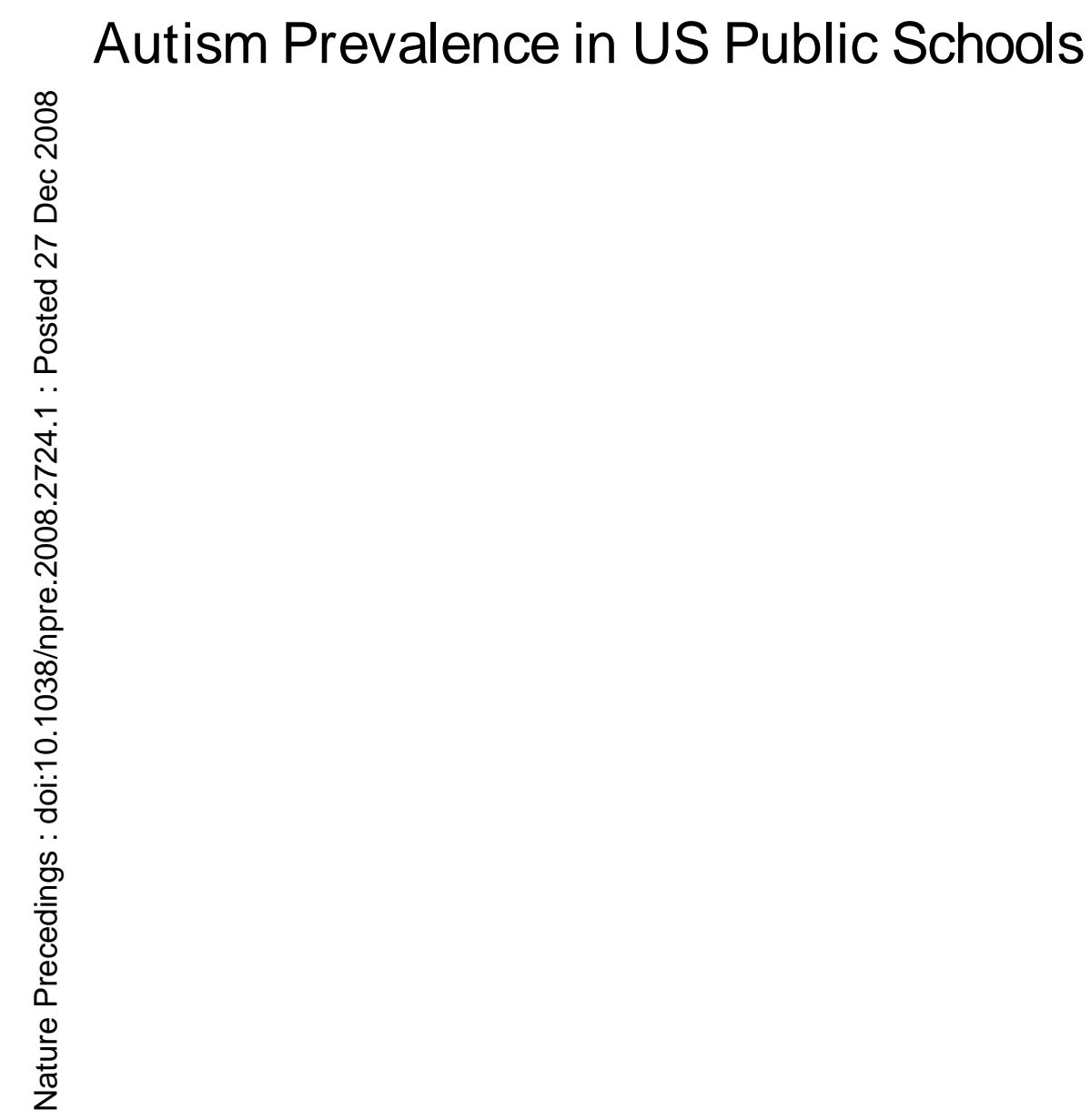

http://www.fightingautism.org/
Autism Prevalence, Public Schools State Rankings, 2006-2007 School Year

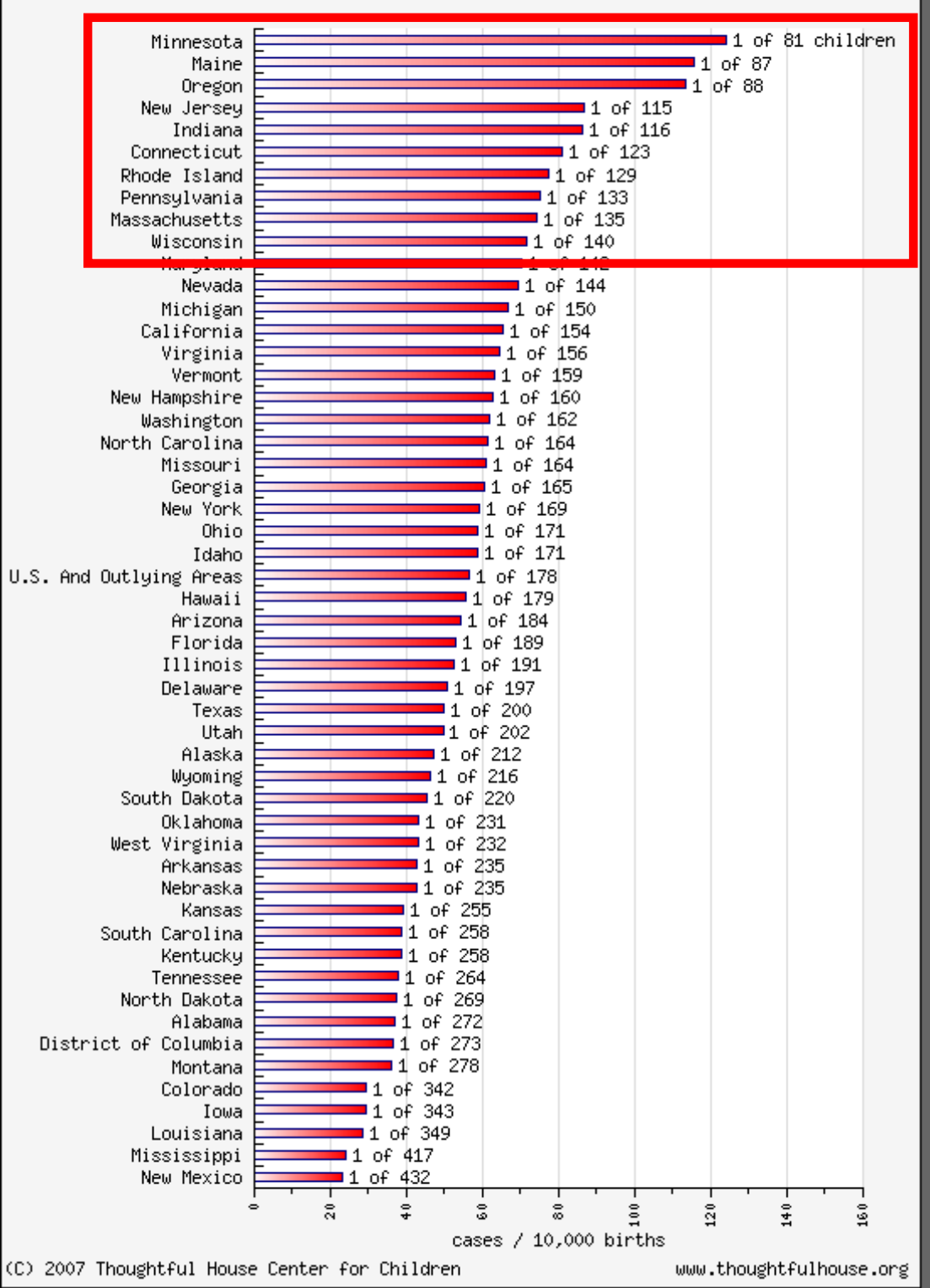




\section{Autism Prevalence in US Public Schools}

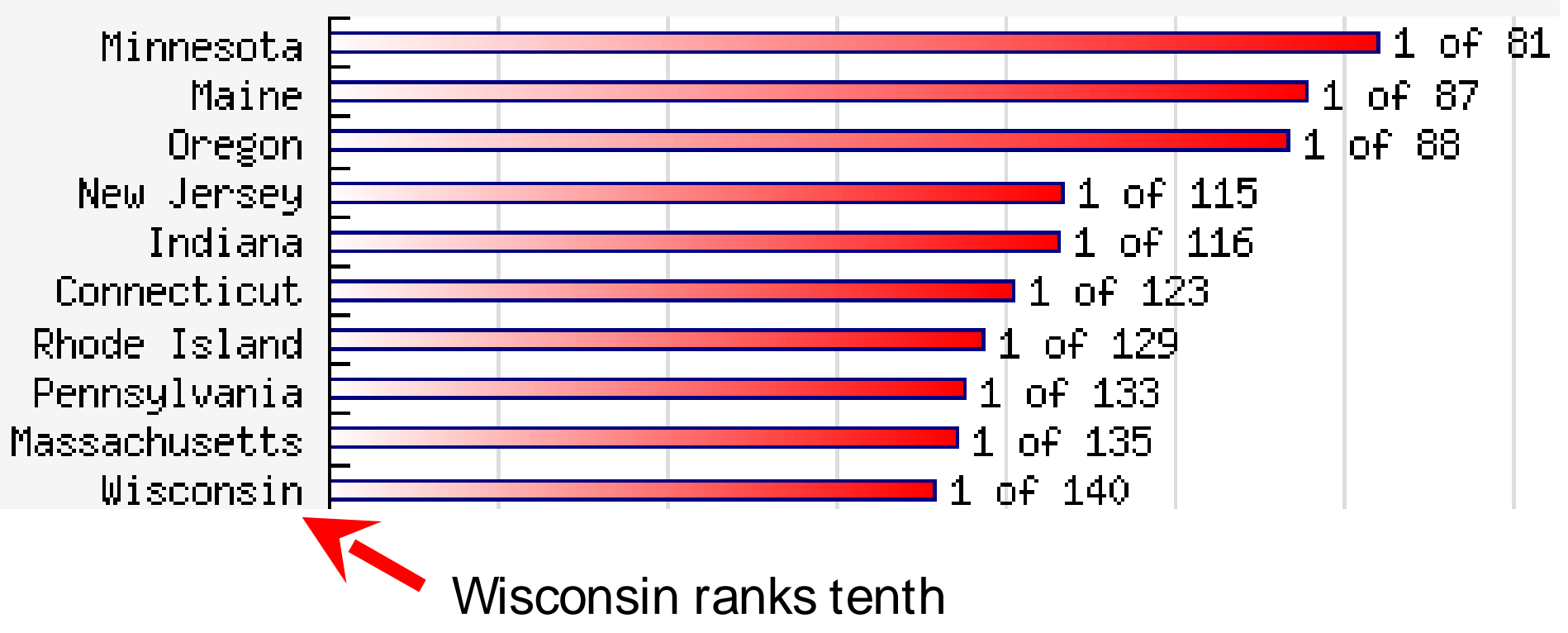

\section{6-2007 Prevalence: 1/140 K-12 students}

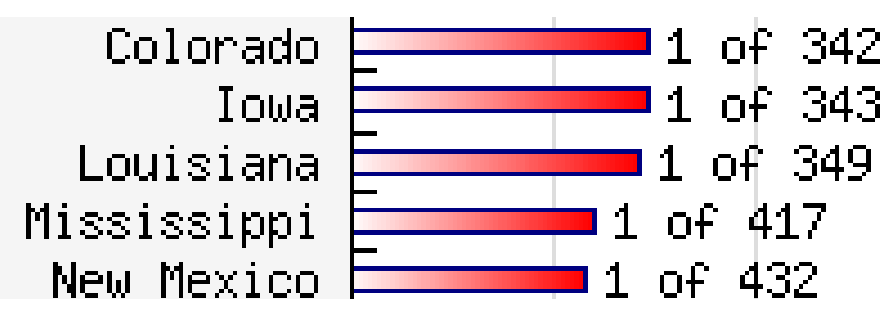




\section{Autism is Behaviorally Defined}

Wing' $s$ Triad

(Wing \& Gould, 1979)

Impaired Social Interaction
Impaired Imagination, Restricted and Repetitive Behaviors

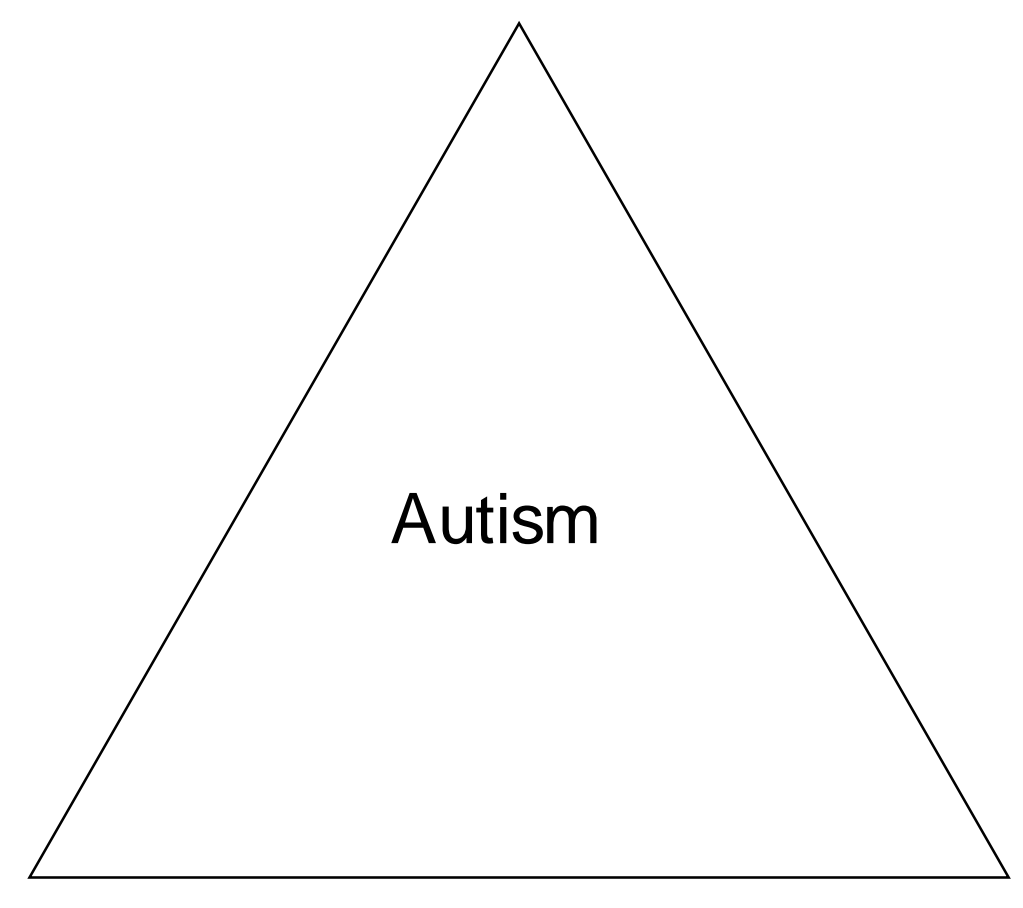

Impaired

Communication

DSM-IV-TR classifies Autism by deficits in these three domains. 
Hypothesis: Dysfunctional networks of facial affect processing may contribute to the impairment in autism social behavior.
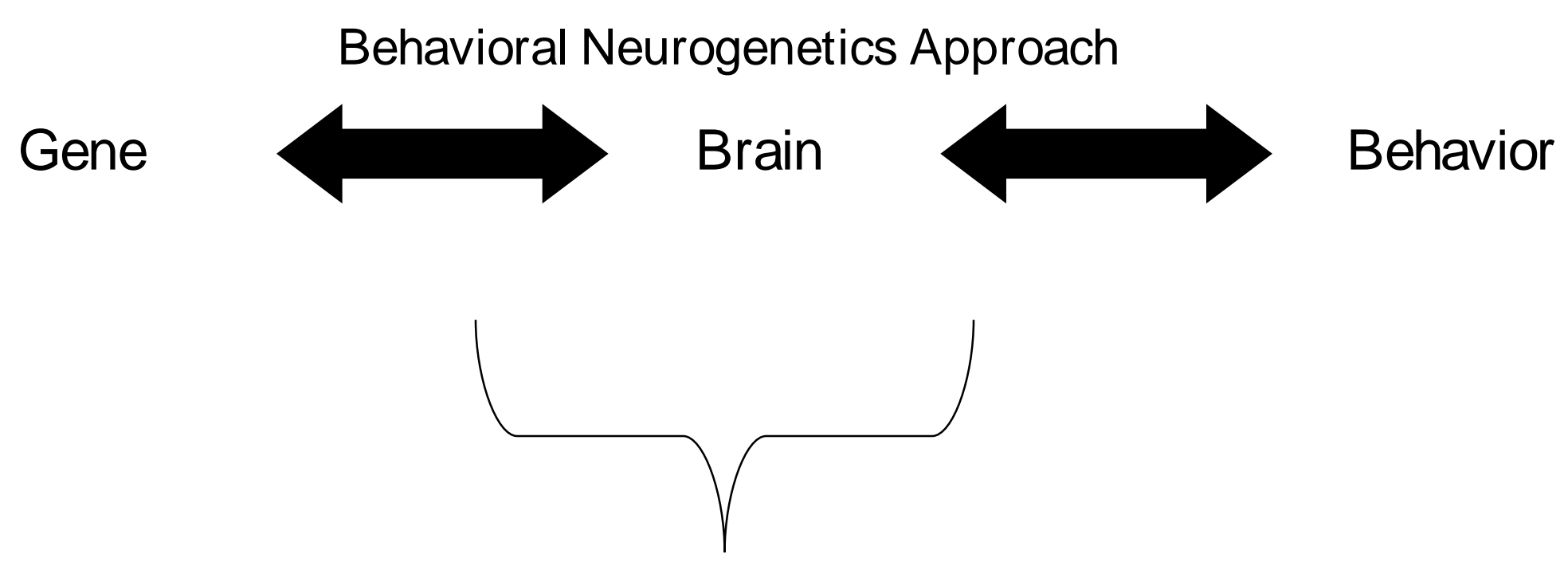

Autism

Connectome 
The Human Connectome is Comprised of Neural Elements and Their Connections

Connectome refers to the " connection matrix of the brain"

Neural elements are defined at multiple scales.

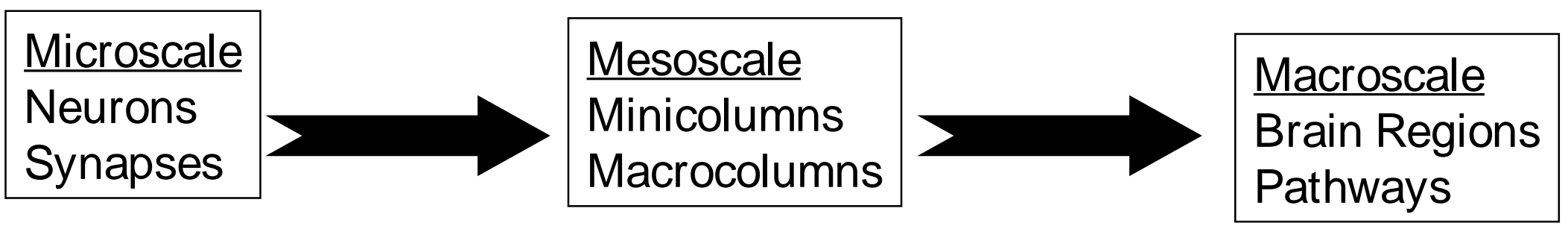




\section{Functional Autism Connectome}

-Neuronal Circuit Development

Microscale

-Genetic Model for Functional Synaptic Communication

Mesoscale

-Implications of Minicolumns to Macroscale Function

Macroscale -Functional Connectivity (FC) of Autism Affective Face Processing Networks (AFPN) 


\section{A Genetic Model of Autism is Fragile X (FX) (Hagerman, 2005 and 2007)}

$\sim 30 \%$ of FX individuals have autism

-Fragile X Mental Retardation Gene (FMR1) codes for FMRP, an mRNA shuttle

-In FX, CGG repeat expansion leads to FMRP loss

-FMRP binds mRNA of AC, an enzyme producing cyclic AMP (CAMP)

(Brown V et al., 2001;Miyashiro KY et al., 2003)

-Microscale Functional cAMP Signaling may Affect Neuronal Communication in the Autism Connectome

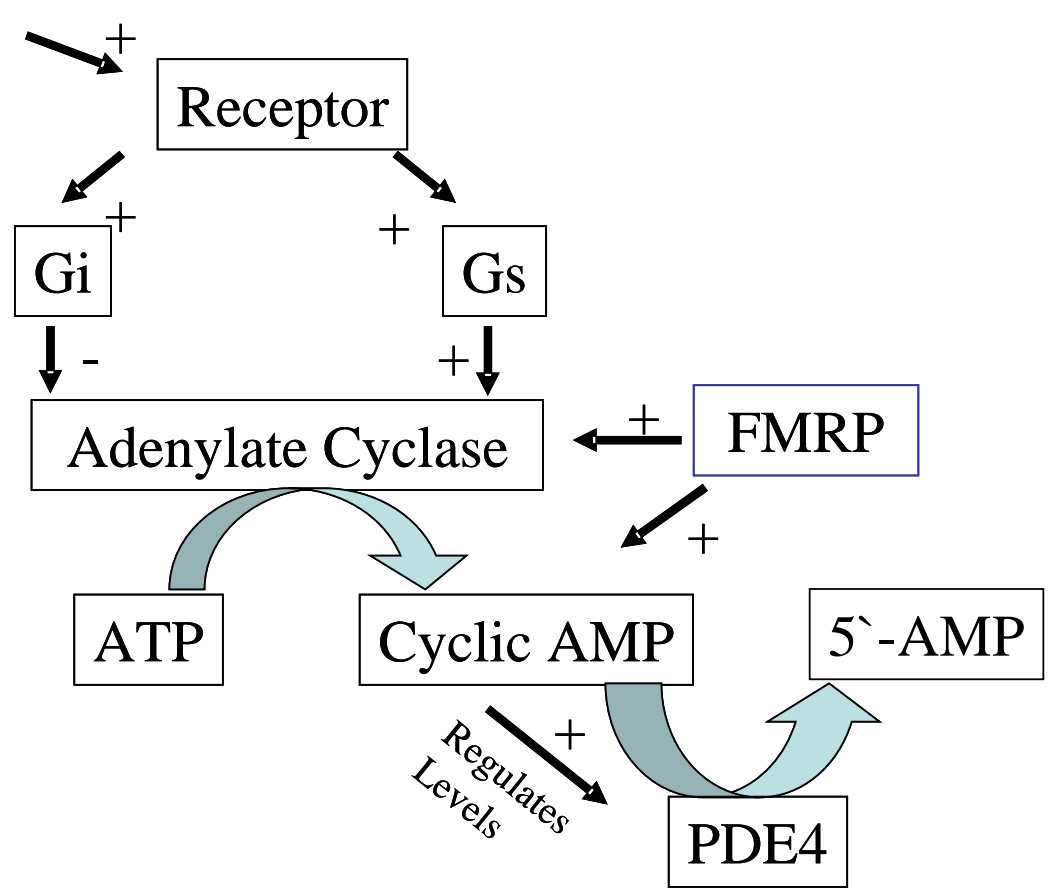

The Cyclic AMP Cascade 


\section{Dissertation Overview}

Microscale

$$
\text { cAMP Signaling in Autism }
$$

FX cAMP induction

CAMP-GEFII is a cAMP target involved in exocytosis (Ozaki et al., 2000) and variants in its gene are associated with autism susceptibility (Bacchelli, 2003)

The mGluR8 receptor has an inhibitory effect on cAMP signaling; and, variants in the mGluR8 gene, GRM8, are associated with an increased susceptibility to autism (Serajee, Zhong et al. 2003) 
Microscale Cyclic AMP involvement in Social and Emotional Behavior in Autism

Opiate Theory of Autism

Autism behavior is related to a hyperactive opiate system (Panksepp 1979)

Opiods reduce the ability of adenylate cyclase to produce cAMP

(Koski and Klee 1981; Childers, Nijssen et al. 1986; Childers 1988; Prather, Tsai et al. 1994).

Opiod antagonist (naltrexone) improves autism behavior in some patients

(Kolmen, Feldman et al. 1995; Riddle, Bernstein et al. 1999; Elchaar, Maisch et al. 2006)

Fetal Valproate Model of Autism

Fetal exposure to the maternal anti-epileptic valproate increases incidence of autism

(Williams, King et al. 2001).

Valproate reduces stimulated, but not basal, cAMP levels

(Montezinho, Mork et al. 2007).

Behaviors of mice exposed to valproate parallel autism

(Ingram, Peckham et al. 2000; Wagner, Reuhl et al. 2006).

Valproate produces overconnectivity of cortical microcircuitry

(Rinaldi, Silberberg et al. 2007) 


\section{Dissertation Overview}

Microscale Association between Cyclic AMP and the Functional Connectome

In Aplysia, cAMP can affect structural and functional neural connectivity through synaptic strengthening and formation of presynaptic terminal varicosities

(Schacher et al., 2003)

In rat, cAMP impedes oscillations in parietal cortex upon stimulating the insula 
Citations:

Kelley DJ, Davidson RJ, Elliott JL, Lahvis GP, Yin JC, Bhattacharyya A.

The Cyclic AMP Cascade Is Altered in the Fragile X Nervous System. PLoS ONE. 2007 Sep 26;2(9):e931.

[http://www.plosone.org/article/info\%3Adoi\%2F10.1371\%2Fjournal.pone.0000931]

Kelley DJ, Bhattacharyya A, Lahvis GP, Yin JC, Malter J, Davidson RJ. The Cyclic AMP Phenotype of Fragile $X$ and Autism Neurosci Biobehav Rev. 2008 Oct;32(8):1533-43. Epub 2008 Jun 17.

Kelley DJ. Functional connectivity of affective face processing networks in autism [dissertation]. [Madison (WI)]: University of Wisconsin, Madison; 2008 Fall. Appendix 3, Cyclic AMP in Fragile X Neural Development: Implications for Prenatal Therapy; p. 318-334. 
Minicolumns are the Basic Anatomical and Functional Unit of Cortex

(Buxhoeveden et al., 2002)

Minicolumn

$\sim 30$ micron diameter

80-100 neurons

"pearls on a string"

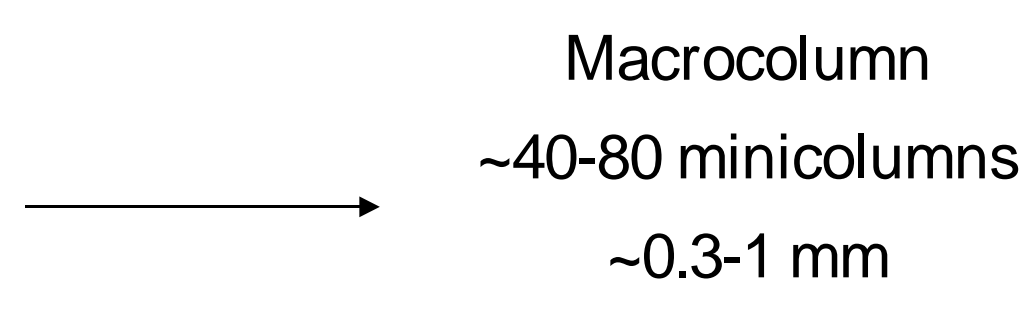

(LaBerge, 2006)

(Rockland et al., 2004)

Autism has an Increased Number of Smaller, Less Compact Minicolumns

(Casanova et al, 2002) 


\title{
Theories Linking Macroscale Connectome Dysfunction to Autism Behavior
}

\author{
Weak central coherence (Frith, 1989) \\ Impaired feature maps (Gustafsson, 1997) \\ Amygdala theory (Baron-Cohen et al., 2000) \\ (Howard et al., 2000)
}

Temporal binding deficit (Brock et al., 2002)

Increased Excitation/Inhibition (Rubenstein et al, 2003)

Underconnectivity hypothesis (Just et al., 2004)

\section{Macroscale \\ Autism \\ Connectome}

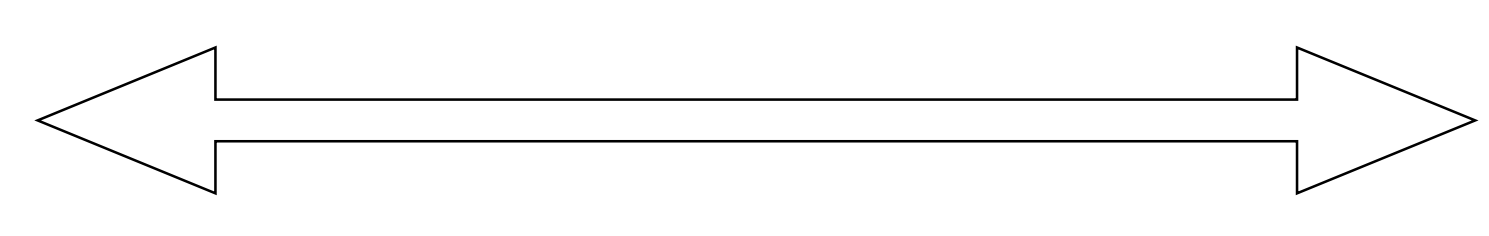

Autism Behavior 


\section{The integrity of functional amygdala circuitry is altered in autism and contributes to task performance behavior.}

\section{Amygdala}
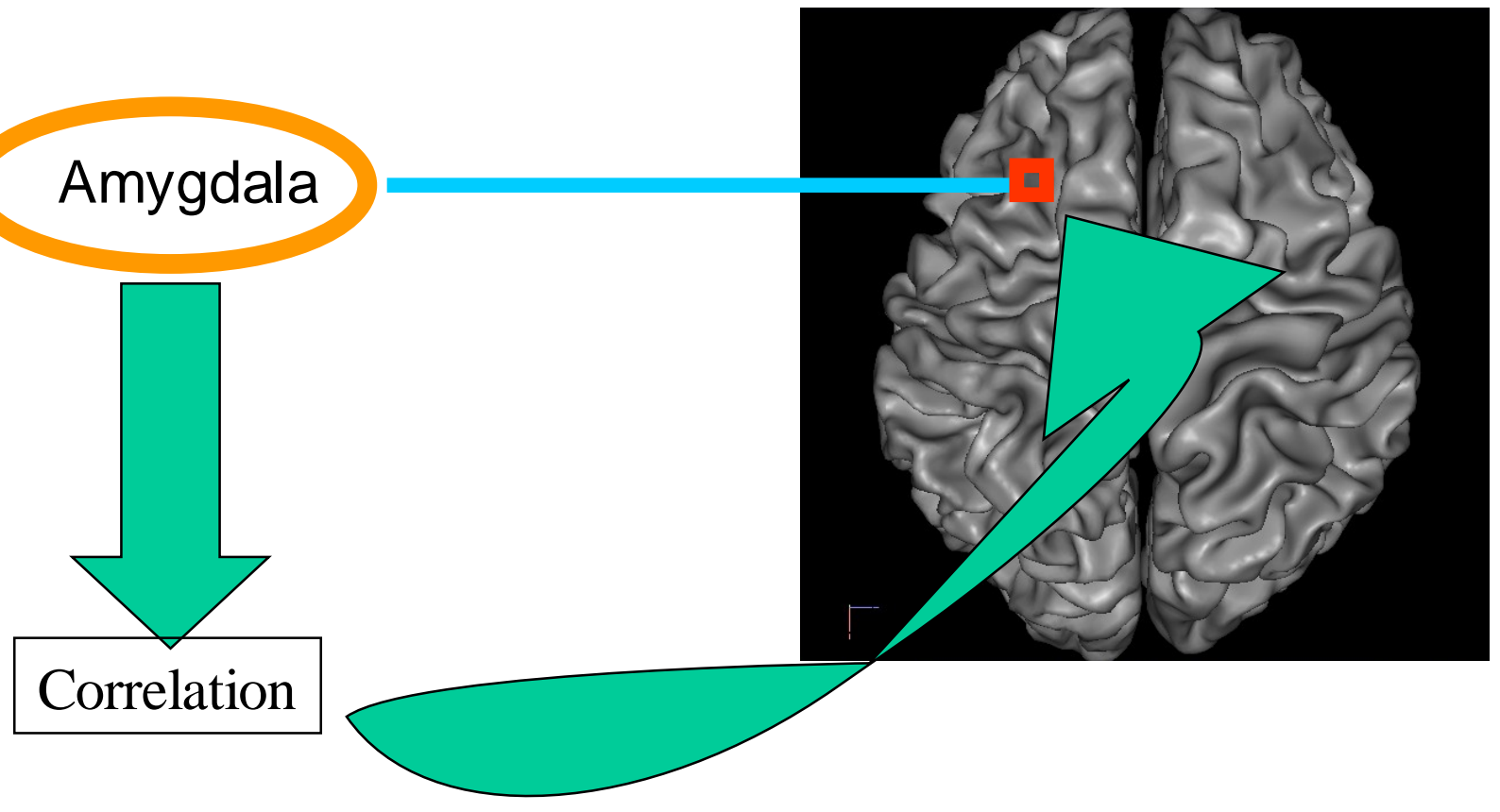

Citation:

Kelley DJ. Functional connectivity of affective face processing networks in autism [dissertation]. [Madison (WI)]: University of Wisconsin, Madison; 2008 Fall. Chapter 2, Abnormalities of Amygdala Connectivity in Autism Predict Gaze Behavior and Deficits in the Decoding of Emotional Faces; p. 19-50. 


\section{Macroscale Network Descriptors to Interpret Results}

\section{Behavioral catalysts}

Nodes involved in transitioning between brain states (Mclntosh 2004).

Multivariability

The ability to form multiple brain states

Metastability

The tendency of brain regions to be both functionally segregated and integrated 


\section{Metastability}

The tendency of brain regions to be both functionally segregated and integrated (Bressler 2003; Fingelkurts and Fingelkurts 2004)

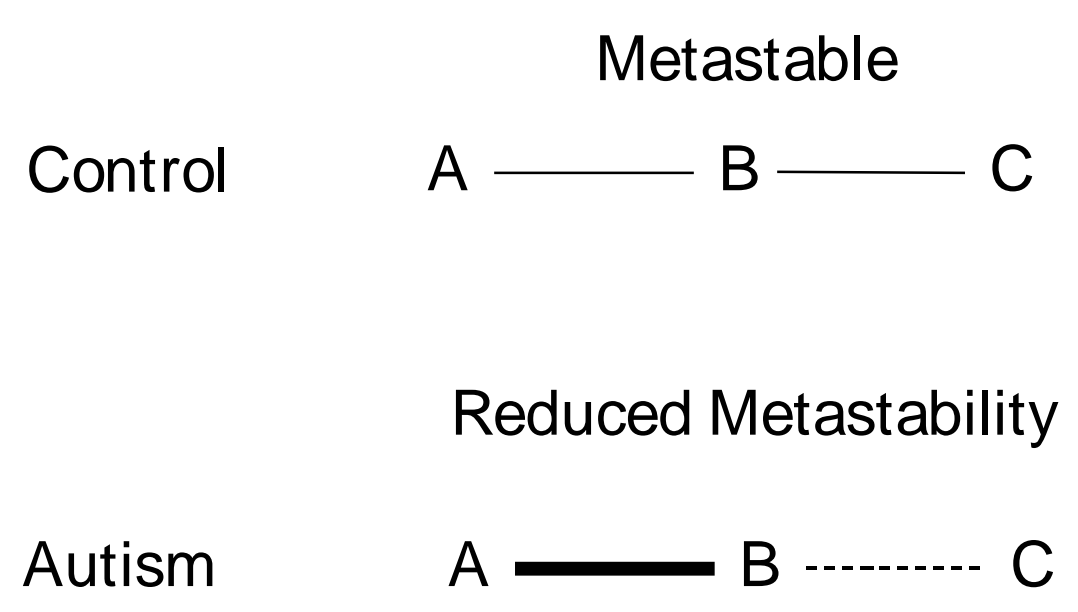

Autism $\quad A \longrightarrow B$ - 


\section{Behavioral Catalyst}

0
0
0
0
0

Nodes involved in transitioning between brain states

(McIntosh 2004)

Resting State

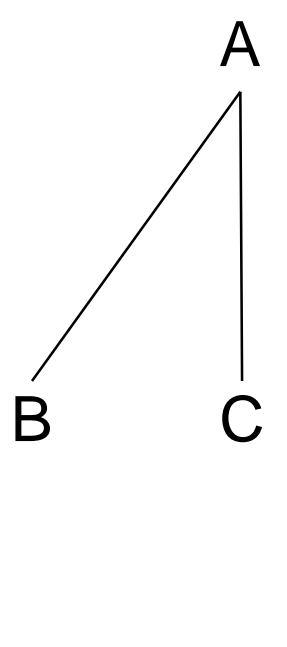

Node A is a Behavioral Catalyst

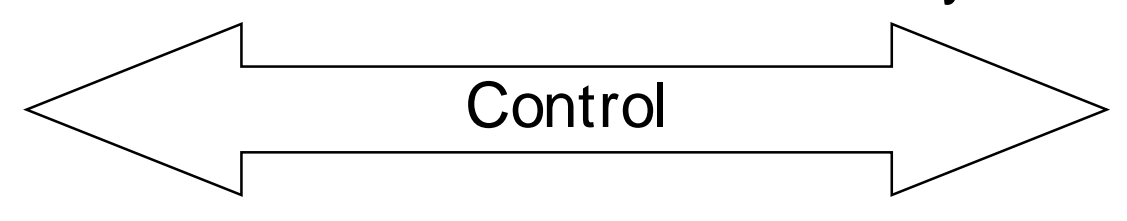

D

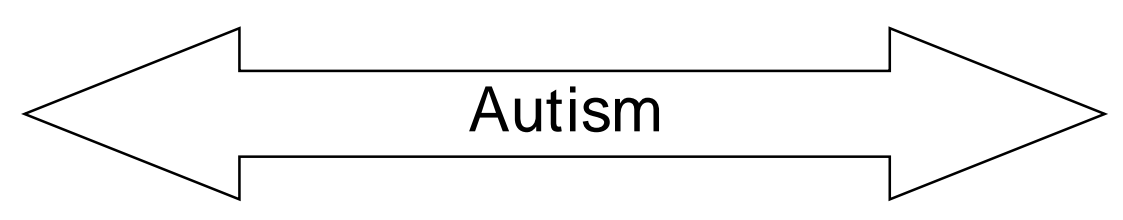

Node A has Reduced Behavioral Catalysis
Emotional Face Processing State
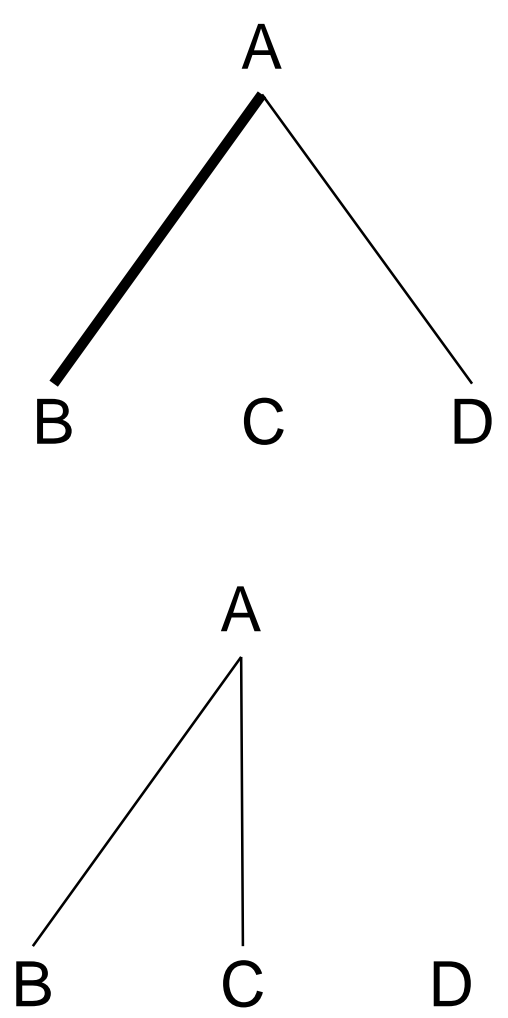


\section{Multivariability}

\section{The ability to form multiple brain states}

(Fingelkurts and Fingelkurts 2004)

Resting State
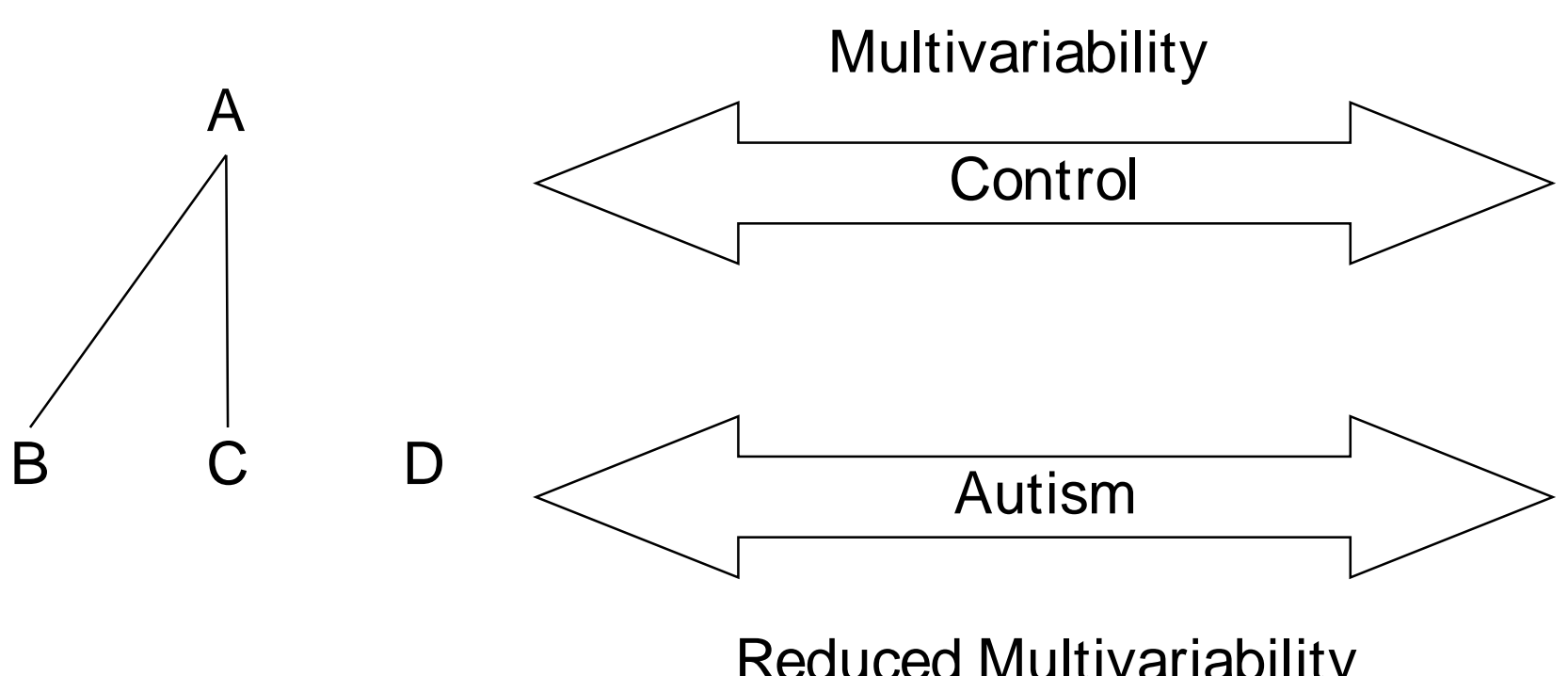

D

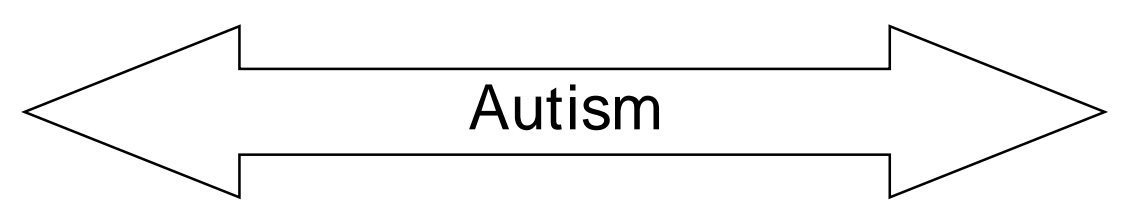

Reduced Multivariability

Emotional Face Processing State
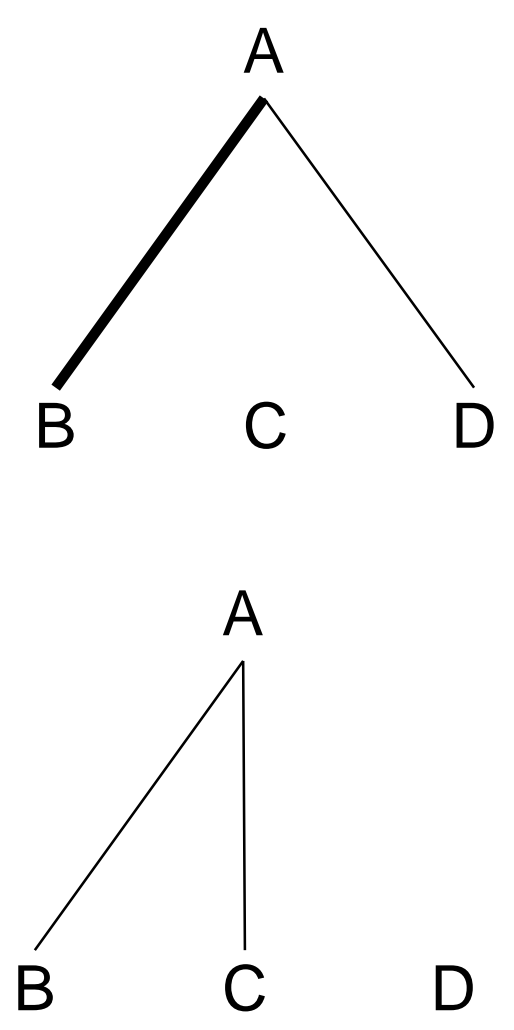
Dysfunctional amygdala connectivity can be distinguished among emotional and neutral face processing networks and resting networks using partial correlation analysis.

Altered connectivity with the amygdala is predictive of autism behavior.

Reduced behavioral catalysis, reduced metastability, and reduced multivariability are consistent features in the autism connectome.

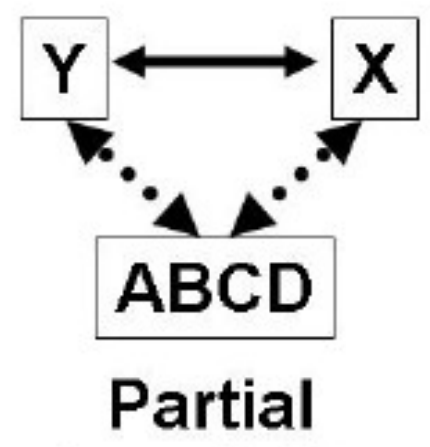

Correlation
Kelley DJ. Functional connectivity of affective face processing networks in autism [dissertation]. [Madison (WI)]: University of Wisconsin, Madison; 2008 Fall. Chapter 3, Amygdala Connectivity in Autism Affective Face Processing Networks; p. 51109.

Kelley DJ. Functional connectivity of affective face processing networks in autism [dissertation]. [Madison (WI)]: University of Wisconsin, Madison; 2008 Fall. Appendix 5, Statistical Approaches to Functional Connectivity of Brain Networks; p. 340-375. 


\section{Conclusion}

Dysfunctionally connected amygdala and interhemispheric affective face processing networks (AFPN) and connectome-behavior relationships distinguish autism and controls.

We reject the underconnectivity hypothesis as a generalizable connectivity framework.

Reduced behavioral catalysis, reduced metastability, and reduced multivariability were consistent AFPN features in the autism connectome.

Gene

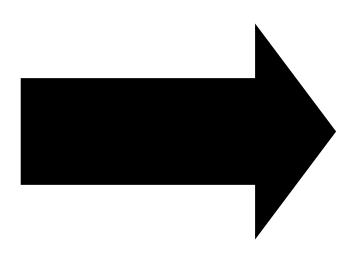

Connectome

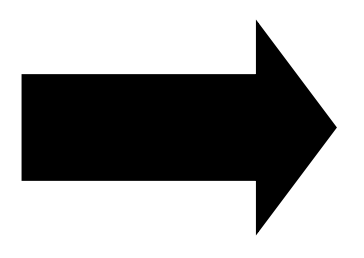

Behavior 


\section{PhD Dissertation Citation:}

Kelley, D.J. (2008). Functional connectivity of affective face processing networks in autism. Dissertation Abstract International, 69(5), 2816B, 458 pages. (UMI No. AAT 3314120 ;ISBN: 9780549628781). Retrieved Decemer 22, 2008, from Dissertations  